\title{
Do female sex fantasies reflect adaptations for sperm competition?
}

\author{
Petri Nummi* \& Jani Pellikka
}

\begin{abstract}
Department of Forest Sciences, P.O. Box 27, Fl-00014 University of Helsinki, Finland ( ${ }^{*}$ corresponding author's e-mail: petri.nummi@helsinki.fi)
\end{abstract}

Received 18 Apr. 2011, final version received 16 Dec. 2011, accepted 20 Dec. 2011

Nummi, P. \& Pellikka, J. 2012: Do female sex fantasies reflect adaptations for sperm competition? - Ann. Zool. Fennici 49: 93-102.

\begin{abstract}
Researchers have suggested that female strategies for sexual selection in humans include the promotion of sperm competition. Sperm competition entails the simultaneous presence of fertile sperm from at least two males in the female's reproductive organ competing for the opportunity to fertilise the ovum. Certain behaviour patterns near ovulation may enable such competition. In this paper, we describe relative preferences for female sexual fantasy types and explore the idea that these preferences may help us understand the settings and mechanisms that promote sperm competition, and discourage interfemale competition. To expand this exploration, we also examine whether preferences vary with respect to the menstrual cycle. Our preliminary findings indicate notable preferences among females for multiple male-partner fantasies over multiple female-partner fantasies or fantasies that include multiple male and female partners. This suggests that females find multipartner settings as arousing as males do, but the psychological mechanism relating to settings that include the presence of same sex competitors may differ from that of males. We also discovered some indications that the female preference for promoting sperm competition and avoiding interfemale competition is the highest and strongest near ovulation.
\end{abstract}

\section{Introduction}

Although Darwin (1871) emphasised the important role of female choice in sexual selection as early as the late 19th century, evolutionary studies have long since underrated this notion (Anderson 1994). This tendency was partly due to the fact that the female role can be very cryptic and include a multitude of behavioural and physiological patterns (Ebenhard 1996). Increasing evidence in recent decades suggests that female sexual selection is a composite of many parallel and sequential functions of which those that promote sperm competition are important throughout the animal kingdom (e.g. Birkhead \& Møller 1998, Shackelford et al. 2005).

Human females often settle on long-term mating as a reproductive strategy (e.g. Graziano et al. 1993, Buss 2003). Sometimes, however especially near ovulation - females and males are more likely to engage in parallel short-term relationships (i.e. extra-pair copulation, EPC; see Gangestad \& Simpson 2000). In his classic work on the subject, Smith (1984) reports that female extramarital sex occurs in $73 \%$ of indexed societies and is common in $57 \%$. Nowadays, the 
EPCs in human females range from $15 \%$ to $50 \%$ in a given population (Shackelford et al. 2006, Drigotas \& Barta 2010), and the average percentage of offspring sired by males other than their putative fathers (i.e. extra-pair paternity, $\mathrm{EPP}$ ) is about $10 \%$, ranging from $1 \%$ to $30 \%$ in different populations (Gangestad 2006, Platek \& Shackelford 2006). In evolutionary terms, EPCs appears to serve as means to ensure the procurement of good genes for offspring. The behaviour may in certain circumstances result in the promotion of sperm competition, i.e. the accumulation of fertile sperm from at least two males in a female's reproductive organ in competition for the opportunity to fertilise the ovum (Birkhead 2000, Gallup et al. 2006).

The relevance of sperm competition as a selective force among humans is controversial (e.g. Pound et al. 2006), although it enjoys the support of evidence that competitive sperm covaries positively with a mate's symmetry and facial attractiveness (Manning et al. 1998, Soler et al. 2003) - good indicators of a potential father's genetic quality (Møller \& Swaddle 1997, Gangestad \& Thornhill 1998). Suggested indications of female adaptations that may promote sperm competition include the use of orgasm in sperm selection (Baker \& Bellis 1993, Thornhill et al. 1995) and double matings (i.e. copulating with another partner within a few days around ovulation) (Bellis \& Baker 1990, Gallup et al. 2006). Plausible indications of male precopulatory adaptations relate to a partners' mate retention behaviour, such as sexual jealousy (Gangestad et al. 2002), manifested in mate guarding and frequent in-pair copulation (Shackelford et al. 2006). These behaviours are related to the fact that men appear to have more knowledge of women's high fertility during the menstrual cycle than it was thought earlier (Kuukasjärvi et al. 2004, Thornhill 2006). Suggested indications of postcopulatory strategies relate to scrambling or displacing rival semen (Pound et al. 2006) or using within-pair sexual coercion when facing the risk of cuckoldry (Goetz \& Shackelford 2006, Camilleri 2009). These interpretations are supported by findings on variations in sperm volume (Baker \& Bellis 1993), penis structure and usage (Gallup et al. 2003) and male interest in visual cues of sperm competition (Pound 2002).
Recently, Gallup et al. (2006) examined patterns of multiple matings among female college students. They found that $13.4 \%$ of the females, who had been in a committed relationship, reported that they had had sex with two or more males in a 24 hour period (i.e. double matings, Bellis \& Baker 1990, see above). Moreover, 11\% of the respondents indicated having participated in group sex, i.e. they had had multiple concurrent male partners. So, the frequency of double matings and threesomes appears sufficient to make sperm competition in humans a relevant matter although they may not be too common nowadays (e.g. Adimora et al. 2011). Accordingly, Pound (2002) suggested that human males show high interest in media content that portrays sexual activity between a female and many males. Sexual fantasies that include multiple concurrent partners are common among males and relatively common among females (e.g. Arndt et al. 1985, Rokach 2001, Shackelford et al. 2005).

Such fantasies, in fact, may provide interesting insight into the psychological mechanisms relating to suggested sperm competition. Actual behaviour, as opposed to fantasies, is more influenced by a combination of external or internal factors and may pose a challenge to attempts to shed light on certain mechanisms (e.g. Udry \& Billy 1987, Ellis \& Symons 1990, Leitenberg \& Henning 1995, Buss 1998, Pound et al. 2006). Even though mechanisms connecting certain contents of sexual fantasies and actual behaviour have proved to be far from simple and obvious, available evidence more often suggests a positive rather than negative relationship between them (Hicks \& Leitenberg 2001, see Williams et al. 2009 for sexually deviant fantasies). It has been found, for example, that women with declining fertility have more frequent and intense sexual fantasies, are more willing to engage in sexual intercourse, and report actually engaging in sexual intercourse more frequently than women in other age groups (Easton et al. 2010).

In accordance with Rokach (2001), we defined sexual fantasies as any daydreaming that includes erotica and that is sexually stimulating. One may assume that females feel safe in their own fantasies and are largely free from guilt or 
the influence of other factors relating to social norms, and thus believe that fantasies may reflect even female desires that would not be expressed in their behaviour. The very nature of fantasies also encompasses the possibility for the female to freely imagine the course of events (Leitenberg \& Henning 1995), and thus to "select" pleasant participants/males in her fantasies.

In this study, we explored the idea that relative preferences between sexual fantasies, which vary in content in terms of the number and gender of the partners, reflect different advantages in maintaining evolutionary function in sexual selection. Assuming that fantasies associate with the promotion of sperm competition, women should prefer fantasies in which the female does not compete with other females, but can promote sperm competition between males. On the contrary, a female should avoid competing with other females without being able to promote sperm competition. Among those situations where a female must compete against other females, she would prefer to have most advantages with respect to reproductive value (i.e., being under 25 years of age; Pawlowski \& Dunbar 1999). During her menstrual cycle, a female should promote sperm competition especially during ovulation, as reflected in both her fantasies and behaviour (Bellis \& Baker 1990, Gangestad \& Cousins 2001, Gangestad et al. 2005).

We hypothesized that irrespective of the female's past sexual behaviour, we should observe following relative preferences regarding different fantasy types:

Competition prediction 1: Females would find fantasies that include themselves and multiple male partners (hereafter FMM) fantasies more arousing than fantasies that include themselves, another female partner and one (hereafter FFM) or more (hereafter FFMM) male partners.

Competition prediction 2: Females would find FFMM fantasies more arousing than FFM fantasies.

Competition prediction 3: Females under the age of 25 would find FFM or FFMM fantasies more arousing than would females at the age of 25 or higher.
Hormonal prediction: Females near ovulation would find FMM fantasies more arousing than would females who are going through other phases of the menstrual cycle.

We tested the plausibility of the above-mentioned predictions using questionnaire data.

\section{Material and methods}

\section{Subject and data}

A group of female students and employees, mainly from Finnish universities and polytechnics, were asked to participate in a study enquiring about their sexual preferences and to provide us with e-mail addresses for further contact. Those who volunteered received an e-mail that included a short introduction to the study and a link to a questionnaire form on the internet page that recorded responses anonymously.

\section{Questionnaire}

The authors of this study designed the questionnaire form based on the above-mentioned hypotheses. The respondents were first asked to provide information about their background. This information included age, indicating reproductive value (categorical classes 15-19, 20-24, 25-29, 30-34, 35-39, 40-45), and information about the time (in days) to the next menstruation. The latter served as a proximate measure of the phase of the menstruation cycle. As control variables we used the type of contraception that the respondent was using, her sexual experience in terms of the number of male and female partners she had had, and her current relationship status.

The respondents were then asked to imagine fantasies that included alternative combinations of the number [one, two or more)] and gender of partners, and to report the relative ranking of sexual fantasies regarding the excitement these combinations awoke. One specific question asked was, "While imagining an erotic fantasy, how excited would you feel if you were in a situation in which: (1) you and one male were engaged in sexual intercourse, (2) you were 
engaged in sexual intercourse with two or more males, (3) you and one or more females were engaged in sexual intercourse with one male or (4) you and one or more females were engaged in sexual intercourse with two or more males?".

In addition to the question about fantasy preferences, respondents were asked to rank their level of sexual excitement associated with the above-mentioned alternatives when portrayed in (1) an erotic story, (2) a photograph or (3) a film. These three questions served as control variables in an attempt, as Janssen et al. (2003) suggested, to test whether the results were sensitive to differences in the respondents' arousal to the sexual stimuli. An open-ended question served to enquire about the respondents perceptions about the origins of their preferences. We designed a pilot questionnaire with a selected set of questions using feedback from 29 females in order to ensure that all the respondents understood the questions similarly and correctly. At that stage, we asked no questions about the type of contraceptive they used or the participants' experience of multipartner sex. We included the pilot responses in our dataset, so the number of responses to different questions varies.

\section{Analyses}

We evaluated competition predictions 1 and 2 by testing whether each respondents' relative rankings for those types of fantasies differed significantly from probabilities expected by chance $(0.50)$. We analysed the relative rankings with a Wilcoxon signed ranks test (hereafter sign test). To test competition prediction 3 , which relates to the greater preference for FFM or FFMM at the age of highest fecundity, we divided the respondents into "high fertility" or "low fertility" groups by using "age under 25 years" as the criterion for high fertility. The statistical significance of rankings assigned to the types of fantasy in question between the groups were tested using the MannWhitney $U$-test.

All pregnancies can be attributed to intercourse during the six-day period ending on the day of ovulation (e.g. Wilcox et al. 1995, Dunson et al. 1999). Since we did not directly measure the respondents' state with respect ovulation, we created a set of 6-day fertility intervals beginning with a 16- to 22-day interval and ending with a 10- to 16-day interval before the onset of the next menstruation. We assumed that this set of intervals included the true fertility period (including ovulation) of all the respondents. By using each of these intervals in a sequence as a criterion for dividing the respondents into "fertile" or "non-fertile" groups, we explored by applying the Mann-Whitney $U$-test whether the mean ranking attributed to the type of fantasy in question differed between the groups. This statistical elaboration allowed us to examine the plausibility of the hormonal prediction, as well as the sensitivity of our result regarding the inaccuracy of our measurement.

Each test was carried out both with and without those respondents who reported having experience of the specific type of multiple sex partners. To test whether the result for alternative fantasy types leads to conclusions similar to those made by using the question on erotic novels, photographs or films, we used a sign test for each pair of variables.

\section{Results}

\section{Responses}

We received responses from 119 persons (i.e. all those persons who provided us with e-mailaddresses). Because we are exploring the plausibility of evolutionary explanations with respect to the sexual preferences of respondents of varied backgrounds, we find that our non-response rate (30\% of those preliminary contacted) is not an important source of bias.

The background questions revealed that the median age class of the respondents was 25-29, most of whom $(69 \%)$ were currently in a relationship, and $58 \%$ of whom used hormonal contraception (Table 1). The median age of first sexual experience was 17 (mean $\pm \mathrm{SD}=16.8$, $\pm 2.09, n=78$ ), and the median number of sex partners was $7($ mean $\pm \mathrm{SD}=11.2 \pm 12.43, n$ $=112)$. More than one quartile $(28 \%)$ of the respondents reported that they had had sex with multiple partners (see Table 1 for details). 
Fig. 1. The priorities (as relative rankings) respondents gave to the four most popular fantasy types $(\mathrm{FM}=$ one female, one male; FMM = one female, two or more males; FFM = two or more females, one male; FFMM = two or more females, two or more males)

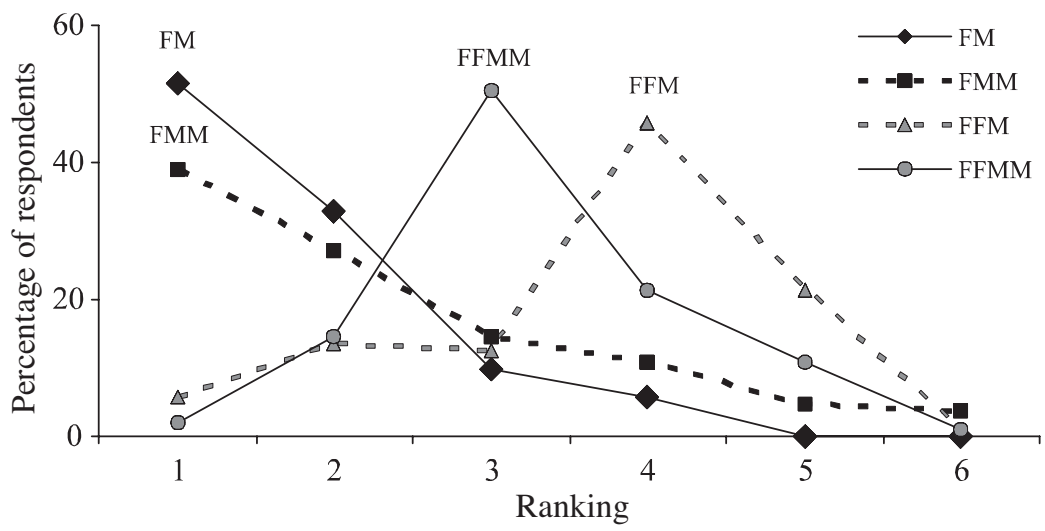

\section{Types of fantasy preferences}

The pattern of ranks assigned to various fantasy types showed an interesting pattern (Fig. 1). The respondents assigned highest ranks to FM fantasies (mean $\pm \mathrm{SD}=1.59 \pm 0.79, n=113$ ). For example, $57 \%$ of the respondents viewed FM as their most preferred fantasy, whereas $30 \%$ of the respondents rated it as the second best. It was more popular than FMM fantasies (sign test; $z=$ $-3.17, n=113, p=0.002$ ), FFM fantasies (sign test: $\left.z=-8.29, n=113, p_{2 \text {-sided }}<0.001\right)$ or FFMM fantasies $(z=-7.62, n=113, p<0.001)$. From the perspective of our hypotheses, it is however more interesting that many respondents assigned high ranks to FMM fantasies (mean $\pm \mathrm{SD}=$ $2.12 \pm 1.08, n=113$ ): $35 \%$ of the respondents rated FMM as their preferred fantasy, and 34\% as the second best. The proportion of respond- ents that viewed FFM fantasies (mean $\pm \mathrm{SD}=$ $3.35 \pm 0.93, n=113$ ) or FFMM fantasies (mean $\pm \mathrm{SD}=2.92 \pm 0.73, n=113$ ) as most preferred (1) or the second best (2), were 5\% and $16 \%$ for FFM fantasies and, 4\% and 18\% for FFMM fantasies, respectively.

\section{Competition predictions}

Both parts of competition prediction 1 were supported by the data (Fig. 2), since respondents preferred the FMM fantasies to the FFM fantasies (sign test: $z=-5.961, n=113, p_{1-\text { sided }}<0.001$ ), as well as to the FFMM fantasies $(z=-5.174$, $\left.n=113, p_{1 \text {-sided }}<0.001\right)$. The difference was statistically significant even after excluding from the analysis those respondents who had reported having experience of either of these types

Table 1. A summary of the respondents' background information.

\begin{tabular}{|c|c|c|c|c|c|}
\hline Variable & $n$ & Min & Max & Median & Percentage \\
\hline Age (categories $18-20, \ldots, 40-45)$ & 109 & $15-20$ & $40-45$ & $20-25$ & \\
\hline Education ( 1 = comprehensive school, ..., 4 = university) & 53 & 1 & 4 & 4 & \\
\hline Relationship $(1=$ single, 2 = dating, $3=$ married $)$ & 81 & 1 & 3 & 2 & \\
\hline Sexual orientation ( 1 = lesbian, 2 = heterosexual, 3 = bisexual) & 81 & 1 & 3 & 2 & \\
\hline Time to next menstruation (days) & 80 & 0 & 35 & 17 & \\
\hline Age at first copulation (years) & 78 & 13 & 23 & 17 & \\
\hline Sex partners during the previous year (indiv.) & 113 & 0 & 12 & 1 & \\
\hline Sex partners, total (indiv.) & 112 & 0 & 60 & 7 & \\
\hline Satisfaction in current sex life $(1=$ very satisfied, $\ldots, 5=$ very unsatisfied $)$ & 53 & 1 & 4 & 2 & \\
\hline Hormonal contraception in use & 53 & & & & 58 \\
\hline Experience of FFM sex & 81 & & & & 16 \\
\hline Experience of FMM sex & 81 & & & & 6 \\
\hline Experience of FFMM sex & 81 & & & & 4 \\
\hline Experience of FM sex & 81 & & & & 98 \\
\hline
\end{tabular}




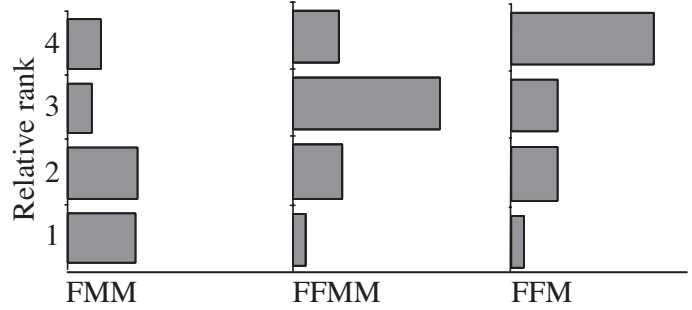

Frequency of respondents

Fig. 2. The frequencies of respondent preferences ( $n=119)$ for fantasy types FMM, FFMM and FFM. Note that rankings of the types are constrained (i.e. not independent). According to our competition predictions, relative rankings between fantasy types should be $F M M<F F M M<F F M$.

$\left(z=-4.801, n=64, p_{1-\text { sided }}<0.001\right)$. Females who reported having had the FMM experience did not have different relative preferences for FMM fantasies as compared with those who did not have such experience (Mann-Whitney $U$-test: $z=$ $\left.-1.182 ; n=81 ; p_{2 \text {-sided }}=0.28\right)$. Similar observation was made regarding FFM experience and FFM preferences (Mann-Whitney $U$-test: $z=-1.624$, $\left.n=81, p_{2 \text {-sided }}=0.10\right)$ and regarding FFMM experience and FFMM preferences (Mann-Whitney $U$-test: $z=-1.056, n=81, p_{2 \text {-sided }}=0.37$ ).

The data also supported competition prediction 2: The respondents ranked FFMM fantasies more often as more arousing than FFM fantasies (signed test: $z=-3.29, n=113, p_{1 \text {-sided }}<0.001$ ). The result was insensitive to the background of the respondent, since relatively similar results were gained after excluding those respondents from the analysis who reported having personal experience regarding the type of settings of which they fantasised $\left(z=-3.375, n=64, p_{1 \text {-sided }}\right.$ $<0.001)$.

In contrast, we found no evidence to support competition prediction 3, which hypothesised that females at a highly fertile age would prefer FFM fantasies more than would females at a lower fertile age; and contrary to our prediction, younger females showed a significantly lower preference for FFMM fantasies (Mann-Whitney $U$-test: $\left.z=-2.19, n=113, p_{1 \text {-sided }}=0.02\right)$.

\section{Hormonal prediction}

The rankings assigned to the FMM fantasy had

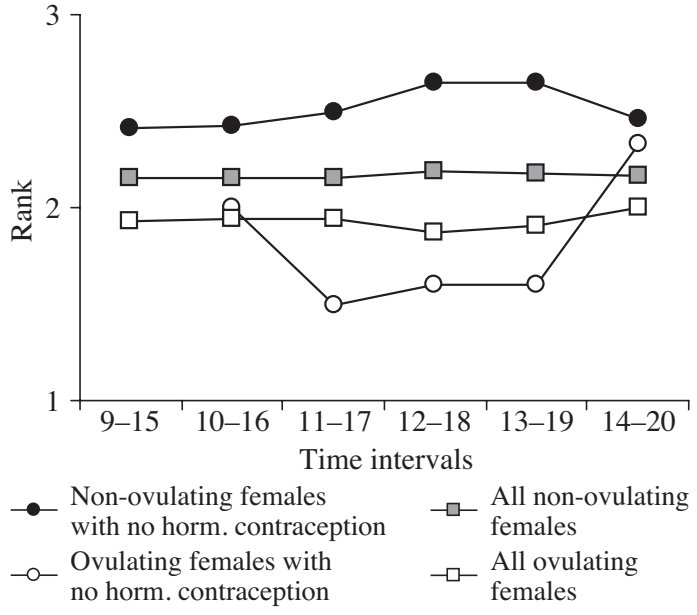

Fig. 3. The mean rankings of respondents' preferences for FMM fantasies over time intervals before the onset of their next menstruation, reported by respondents at the moment of responding. Note that the time categories overlap with each other. The series denoted with squares describe the mean rankings of all respondents, and the circles denote the corresponding values of only those respondents, who were not using hormonal contraception.

characteristics that correspond to the hypothesis according to which the values are higher among females in the fertile phase of the menstruation cycle than among others (hormonal prediction 1; see Fig. 3). However, when the information about the use of hormonal contraception was not taken into account, the difference between mean rankings were not statistically significant with respect to the preferences of other females in any category of the time interval studied. According to our statistical elaboration, by assuming a 10to 16-day interval before the onset of the next menstruation as an interval including the true fertility period of respondents, we discovered no statistically significant difference (MannWhitney $U$-test, interval ${ }_{10-16}: z=-0.64, n=113$ $p_{1 \text {-tailed }}=0.26$ ). The corresponding test that we made by using other time intervals to categorise respondents showed similar pattern (interval ${ }_{11-17}$ : $z=-0.64, n=113, p_{1 \text {-tailed }}=0.26$; interval $_{12-18}: z$ $=-1.03, n=113, p_{1 \text {-tailed }}=0.16$; interval ${ }_{13-19}: z$ $=-0.67, n=113, p_{1 \text {-tailed }}=0.26 ;$ interval $_{14-20} ; z$ $=-0.31, n=113, p_{1 \text {-tailed }}=0.38 ;$ interval $_{15-21}: z$ $=-0.38, n=113, p_{1 \text {-tailed }}=0.35$; interval $_{16-22}: z=$ $\left.-0.95, n=113, p_{1 \text {-tailed }}=0.17\right)$. 
The rankings assigned to FMM fantasies were generally greater among respondents who used no hormonal contraception (Fig. 3), and at some intervals the observed mean difference in mean rank showed a tendency (Mann-Whitney $U$-test, interval ${ }_{10-16}: z=-0.25, n=22, p_{1 \text {-tailed }}=$ 0.64 ; interval $_{11-17}: z=-1.20, n=22, p_{1 \text {-tailed }}=$ 0.24 ; interval $_{12-18}: z=-1.78, n=22, p_{1 \text {-tailed }}=$ 0.056 ; interval $_{13-19}: z=-1.78, n=22, p_{1 \text {-tailed }}=$ 0.056 ; interval $_{14-20}: z=-0.11, n=22, p_{1 \text {-tailed }}=$ 0.38 ; interval $_{15-21}: z=-0.31, n=22, p_{1 \text {-tailed }}=$ 0.41 ; interval $_{16-22}: z=-0.31, n=22, p_{1 \text {-tailed }}=$ $0.46)$.

Although the sample size was small, and thus also the power of the test to detect statistically significant differences is low, it seems that the result was unaffected by the females' experience (only one female using no hormonal contraception had experience of this type of sex).

\section{Association of fantasies with different media}

The rankings assigned to FMM fantasies were higher (mean rank $\pm \mathrm{SD}=2.12 \pm 1.09, n=$ 113) than the values assigned to this type if it appeared in an erotic story (mean rank $\pm \mathrm{SD}=$ $2.30 \pm 1.18, n=113$ ), a photograph (mean rank $\pm \mathrm{SD}=2.53 \pm 1.11, n=113$ ) or a film (mean rank $\pm \mathrm{SD}=2.47 \pm 1.13, n=113)$. In addition, we found that perceptions of the excitement of the FMM alternative when reading erotic stories were higher than the excitement of seeing it in a photograph (signed test: $z=-2.58, n=113$, $\left.p_{1 \text {-sided }}=0.01\right)$ or a film $\left(z=-2.07, n=113, p_{1 \text {-sided }}\right.$ $=0.04)$. Those options were ranked more or less similarly $\left(z=-0.66, n=113, p_{1 \text {-sided }}=0.51\right)$.

A reversed pattern emerged when analysing the FFM alternative: for this option, FFM fantasies were considered less exciting (mean rank $\pm \mathrm{SD}=3.35 \pm 0.93, n=113$ ) than values of erotic stories (mean rank $\pm \mathrm{SD}=3.12 \pm 0.94, n$ $=113$ ), photographs (mean rank $\pm \mathrm{SD}=2.99 \pm$ $1.00, n=113$ ) or films (mean rank $\pm \mathrm{SD}=3.09$ $\pm 1.02, n=113$ ). Among the alternatives, only the preference for FFM fantasies showed statistically significant difference as compared with that of an erotic story (signed test: $z=-3.08, n=$ $\left.113, p_{2 \text {-sided }}=0.002\right)$, a photograph $(z=-3.39, n=$ $\left.113, p_{2 \text {-sided }}=0.001\right)$ or a film $(z=-2.92, n=113$, $\left.p_{2 \text {-sided }}=0.004\right)$.

Interestingly, photographs (mean rank $\pm \mathrm{SD}$ $=2.81 \pm 0.94, n=113$ ) or films (mean rank \pm $\mathrm{SD}=2.73 \pm 0.87, n=113$ ) that included the FFMM alternative ranked the highest and were nearly similarly viewed as arousing (signed test: $z=-1.17, n=113, p_{2 \text {-sided }}=0.24$ ); the FFMM fantasies ranked lower (mean rank $\pm \mathrm{SD}=2.92$ $\pm 0.73, n=113$ ), and the FFMM stories (mean rank $\pm \mathrm{SD}=3.05 \pm 0.77, n=113$ ) ranked the lowest. The rank of the FFMM fantasies differed statistically from that of films $(z=-2.01$, $\left.n=113, p_{2 \text {-sided }}=0.045\right)$ and showed a tendency with respect to erotic stories $(z=-1.83, n=113$, $\left.p_{2 \text {-sided }}=0.07\right)$. The preferences for erotic stories showed statistically significant differences as compared with that for photographs $(z=-2.00$, $\left.n=113, p_{2 \text {-sided }}=0.046\right)$ or films $(z=-3.50, n=$ $\left.113, p_{2 \text {-sided }}<0.001\right)$.

\section{Discussion}

Female sex fantasies with multiple partners shared many characteristics which can be understood coherently from the perspective of female adaptation to sperm competition. First, respondents in general preferred fantasies that included many male partners to fantasy types that also included other females. The observation that females preferred fantasy types which enable sperm competition and disable competition among other females is in concert with our competition predictions 1 and 2. Second, the indication that the preference for FMM fantasies is higher, and for FFM fantasies lower near the time of ovulation permits the possibility that the result may reveal an inclination to promote sperm competition. This result is also compatible with that of earlier studies revealing that during ovulation, females have the greatest interest in fantasies about non-primary partners (Gangestad et al. 2002, 2005). Moreover, our result is in line with the finding that ovulating females are especially prone to double matings that promote sperm competition (Baker \& Bellis 1990, Gallup et al. 2006). We cannot, however, rule out the possibility that FMM fantasies above all reflect a general female interest for promiscuity (Gangestad \& Simpson 2000, Scelza 2011). 
Surprisingly, Pound (2002) found that males also strongly preferred FMM fantasies to FFM fantasies. Unlike with females, the sperm competition characteristic of FMM sex is not beneficial to men from the point of view of successful reproduction. Consequently, a different mechanism may explain the links between preferences and reproduction. One possible reason for the apparent male preference for FMM fantasies is that male preferences are related more to arousal than to successful reproduction (its consequence): FMM sex could represent a situation in which a male "really must do his best" even though it is not an ideal situation from the point of view of male reproduction. Another explanation for Pound's (2002) observations is to assume that (young) males seek situations in which, in addition to a female sex partner, other males are also present, because the situation may reflect desirability of the female. For example, this explanation may suggest that such a female is open-minded and accessible. In this case, the sexual behaviour of other males is worth imitating (Place et al. 2010). In addition, the presence of many males may indicate that the female either is willing to promote sperm competition or is overpowered by males. The possible problem in Pounds' (2002) work is that the preference of men for FMM sex could reflect the status of the men, which was unknown.

One can argue that our empirical predictions (excluding the "hormonal prediction") could have been deduced from other hypotheses, possibly from socio-cultural ones. However, in our open-ended responses, none of the respondents felt that their preference for FMM sexual fantasies would be culturally supported or created. On the contrary, the only "multi-partner" fantasies reported seen in the media - which may have affected preferences - were FFM fantasies. In addition, the respondents' preferences appeared not simply to reflect what they had or had not experienced, which agrees with the findings of earlier studies (e.g. McCauley \& Swann 1978). The open-ended responses also revealed something about why, in reality, women do not very often participate in FMM sex (Gallup et al. 2006): some respondents associated it with rape, although the form of the question invited one to freely form one's own fantasies. This dem- onstrates how the elements of fantasies are not entirely independent of the assessment of rape risk and may thus be linked to the observed riskaverse behaviour of females during the ovulatory phase (Bröder \& Hohmann 2003). None of the respondents reported viewing the FMM or FFM fantasies as an exercise of power of men or women.

We emphasise that our data sample is too small to draw strong conclusions about female fantasies in general or interactions of several independent variables. We found also some evidence suggesting that respondents were slightly more experienced regarding the number of lifetime partners than were those of the same age in a national survey based on a random sample (Haavio-Mannila \& Kontula 2001). HaavioMannila and Kontula (2001), for example, found that $19 \%$ of females at the age of 18-34 years had had one sex partner in their lifetime, $28 \%$ of females 2-4 partners, $29 \%$ of females 5-9 and $23 \%$ of females 10 or more partners, whereas in our sample those numbers were $11 \%, 20 \%$, $36 \%$ and $43 \%$, respectively. Moreover, the testing of the hormonal explanation would be more accurate if the frequency of the type of fantasies is observed throughout the menstrual cycle (i.e. using longitudinal data) and if the timing of the ovulation is measured accurately. We acknowledge these limitations, but find that our method provided us with tools for gathering sufficient evidence for preliminary answers to our study questions. We also find our way of gathering information promising (i.e. to ask respondents to imagine upon request situations, evaluate them side by side, and rank them). Information about respondents' fantasies has typically been collected retrospectively (e.g. Leitenberg \& Henning 1995): one method is to ask respondents to write down the fantasies they remember or to record them over a given period of time. Female fantasies, however, are typically less explicit than male fantasies (Ellis \& Symons 1990) and may not reveal in detail the fantasy types we studied here, or the relative preference between them. Pelletier and Herold (1988), for instance, reported that females more often fantasized about sex with many men (29\%) than about group sex with males and females (16\%). However, it is unclear whether fantasies remem- 
bered or reported at given time actually reflect the respondents' preferences in general (and not merely some "externally" provoked fantasies, e.g. Jones \& Barlow 1990).

Our findings contribute to the growing body of evidence suggesting that sexual fantasies may provide an interesting perspective on the biologically understandable desires of human behaviour (Ellis \& Symons 1990, Shackelford et al. 2005, Easton et al. 2010). Previous studies focusing on female fantasies have seldom separated more than one or two types of multi-partner fantasies. Our findings, however, clearly indicate that female preferences vary greatly and may be based on evolved psychological mechanisms.

\section{Acknowledgements}

We warmly thank our anonymous female respondents for participating in our study. We also thank Markku Milonoff, Hannu Rita and two anonymous referees for their valuable comments, and Stephen Stalter for carefully checking the language.

\section{References}

Anderson, M. 1994: Sexual selection. - Princeton University Press, Princeton.

Arndt, W. B. Jr., Foehl, J. C. \& Good, F. E. 1985: Specific sexual fantasy themes: a multidimensional study. - Journal of Personality and Social Psychology 48: 472-480.

Baker, R. R. \& Bellis, M. A. 1993: Human sperm competition: ejaculate manipulation by females and a function for the female orgasm. - Animal Behaviour 46: 887-909.

Bellis, M. A. \& Baker, R. R. 1990: Do females promote sperm competition? Data for humans. - Animal Behaviour 40: 997-999.

Birkhead, T. 2000: Promiscuity. An evolutionary history of sperm competition and sexual conflict. - Faber and Faber, London.

Birkhead, T. R. \& Moeller, A. P. (eds.) 1998: Sperm competition and sexual selection. - Academic Press, San Diego.

Bröder, A. \& Hohmann, N. 2003: Variations in risk taking behavior over the menstrual cycle. An improved replication. - Evolution and Human Behavior 24: 391-398

Buss, D. 1998: Sexual sgrategies theory: historical origins and current status. - Journal of Sex Research 35: $19-31$.

Buss, D. 2003: The evolution of desire: strategies of human mating, 2nd ed. - Basic Books, New York.

Camilleri, J. A. 2009. Testing the cuckoldry risk hypothesis of partner sexual coercion in community and forensic samples. - Evolutionary Psychology 7: 164-178.

Clemen, R. 1996: Making hard decisions: an introduction to decision analysis, 2nd ed. - Duxbury Press, CA.

Darwin, C. 1871: The descent of man, and selection in relation to sex [Reprint]. - Princeton University Press, Princeton.

Drigotas, S. M. \& Barta, W. 2010: The cheating heart: scientific explorations of infidelity. - In: Fisher, T. D. \& McNulty, J. (eds.), Current directions in human sexuality and intimate relationships: 192-198. Allyn \& Bacon, Boston.

Dunson, D. B., Baird, B. B., Wilcox, A. J. \& Weinberg, C. R. 1999: Day-specific probabilities of clinical pregnancy based on two studies with imperfect measures of ovulation. - Human Reproduction 14: 1835-1839.

Easton, J. A., Confer, J. C., Goetz, C. D. \& Buss, D. M. 2010: Reproduction expediting: sexual motivations fantasies, and the ticking biological clock. - Personality and Individual Differences 49: 516-520.

Eberhard, W. G. 1996: Female control: sexual selection by cryptic female choice. - Princeton University Press, Princeton.

Ellis, B. J. \& Symons, D. 1990: Sex differences in sexual fantasy: an evolutionary psychological approach. Journal of Sex Research 27: 527-555.

Gangestad, S. H. \& Simpson, J. A. 2000: The evolution of human mating: trade-offs and strategic pluralism. Behavioral and Brain Sciences 23: 573-644.

Gangestad, S. H. \& Cousins, A. J. 2001: Adaptive design, female mate preferences, and shifts across the menstrual cycle. - Annual Review of Sex Research 12: 145-185.

Gangestad, S. H. 2006: Evidence for adaptations for female extra-pair mating in humans: thoughts on current status and future directions. - In: Platek, S. M \& Shackelford, T. K. (eds.), Female infidelity and paternal uncertainity: 37-57. Cambridge University Press, Cambridge.

Gangestad, S. W. \& Thornhill, R. 1998: Menstrual cycle variation in women's preferences for the scent of symmetrical men. - Proceedings of the Royal Society of London B 265: 927-933.

Gangestad, S. H., Thorhill, R. \& Garver, C. E. 2002: Changes in women's sexual interests and their partners materetention tactics across the menstrual cycle: evidence for shifting conflicts of interest. - Proceedings of the Royal Society of London B 269: 975-982.

Gangestad, S. H., Thorhill, R. \& Garver-Apgar, C. E. 2005: Women's sexual interests across the ovulatory cycle depend on primary partner developmental instability. - Proceedings of the Royal Society of London B 272: 2023-2027.

Gallup, G. G. Jr., Burch, R. L., Zappieri, M. L., Parvez, R. A., Stockwell, M. L. \& Davis, J. A. 2003: The human penis as a semen displacement device. - Evolution and Human Behavior 24: 277-289.

Gallup, G. G. Jr., Burch, R. L. \& Berens Mitchell, T. J. 2006: Semen displacement as a sperm competition strategy. Human Nature 17: 253-264.

Graziano, W. G., Jensen-Campbell, L. A., Shebilske, L. J. \& Lundgren, S. R. 1993: Social influence, sex differences, 
and judgements of beauty: Putting the interpersonal back into interpersonal attraction. - Journal of Personality and Social Psychology 65: 522-531.

Haavio-Mannila, E. \& Kontula, O. 2001: Seksin trendit: meillä ja naapureissa. - WSOY, Helsinki.

Hicks, T. V. \& Leitenberg, H. 2001: Sexual fantasies about one's partner versus someone else: gender differences in incidence and frequency. - The Journal of Sex Research 38: 43-50.

Janssen, E., Carpenter, D. \& Graham, C. 2003: Selecting films for sex research: Gender differences in erotic film preference. - Archives of Sexual Behavior 32: 243-251.

Jones, J. C. \& Barlow, D. H. 1990: Self-reported frequency of sexual urges, fantasies, and masturbatory fantasies in heterosexual males and females. - Archives of Sexual Behavior 19: 269-279.

Kuukasjärvi, S., Eriksson, C. J. P., Koskela, E., Mappes, T., Nissinen, K. \& Rantala, M. J. 2004: Attractiveness of women's body odors over the menstrual cycle: the role of oral contraceptives and receiver sex. - Behavioral Ecology 15: 579-584.

Leitenberg, H. \& Henning, K. 1995: Sexual fantasy. - Psychological Bulletin 117: 469-496.

Manning, J. T., Scut, D., Wilson, J. \& Lewis-Jones, D. I. 1998: The ratio of the 2 nd and 4th digit length: a predictor of sperm numbers and consentrations of testosterone, luteinizing hormone and oestrogen. - Human Reproduction 13: 3000-3004.

McCauley, C. \& Swann, C. P. 1978: Male-female differences in sexual fantasy. - Journal of Research in Personality 12: 76-86.

Møller, A. P. \& Swaddle, J. P. 1997: Asymmetry, developmental stability and evolution. - Oxford University Press, Oxford.

Pawlowski, B. \& Dunbar, R. I. M. 1999: Impact of market value on human mate choice decisions. - Proceedings of the Royal Society of London B 266: 281-285.

Pelletier, L. A. \& Herold, E. S. 1988: The relationship of age, guilt, and sexual experience with female sexual fantasies. - The Journal of Sex Research 24: 250-256.

Place, S. S., Todd, P. M., Penke, L. \& Asendorpf, J. B. 2010. Humans show mate copying after observing real mate choices. - Evolution and Human Behavior 31: 320-325.

Platek, S. M \& Shackelford, T. K. 2006. Introduction to theory and research on anti-cuckoldry tactics: overview of current volume. - In: Platek, S. M. \& Shackelford, T. K. (eds.), Female infidelity and paternal uncertainity: 3-13. Cambridge University Press, Cambridge.
Pound, N. 2002: Male interest in visual cues of sperm competition risk. - Evolution and Human Behavior 23: 443-466.

Pound, N., Shackelford, T. K. \& Goetz, A. T. 2006: Sperm competition in humans. - In: Shackelford, T. K. \& Pound, N. (eds.), Sperm competition in humans. Classic and contemporary readings: 3-31. Springer, New York.

Rokach,A. 2001: Content analysis of sexual fantasies of males and females. - Journal of Psychology 124: 427-437.

Shackelford, T. K., Pound, N. \& Goetz, A. T. 2005. Psychological and physiological adaptations to sperm competition in humans. - Review of General Psychology 9: $228-248$.

Shackelford, T. K., Goetz, A. T., Guta, F. E. \& Schmitt, D. P. 2006. Mate guarding and frequent in-pair copulation in humans: concurrent of compensatory anti-cuckoldry tactics? - Human Nature 17: 239-254.

Smith, R. L. 1984. Human sperm competition. - In: Smith, R. L. (ed.), Sperm competition and the evolution of animal mating systems: 601-659. Academic Press, New York.

Soler, C., Nunez, M., Gutierrez, R., Nunez, J., Medina, P., Sancho, M., Alvarez, J. \& Nunez, A. 2003. Facial attractiveness in men provides clues to semen quality. - Evolution and Human Behavior 24: 199-207.

Scelza, B. A. 2011. Female choice and extra-pair paternity in a traditional human population. - Biology Letters 7 : 889-891.

Thornhill, R. 2006: Foreword: Human sperm competition and woman's dual sexuality. - In: Shackelford, T. K. \& Pound, N. (eds.), Sperm competition in humans. Classic and contemporary readings: $\mathrm{v}-\mathrm{x}$ vii. Springer, New York.

Thornhill, R., Gangestad, S. W. \& Comer, R. 1995: Human female orgasm and mate fluctuating asymmetry. Animal Behaviour 50: 1601-1615.

Udry, J. R. \& Billy, J. O. G. 1987: Initiation of coitus in early adolescence. - American Sociological Review 52: 841-855.

Wilcox, A. J., Weinberg, C. R. \& Baird, D. D. 1995: Timing of sexual intercourse in relation to ovulation - effects on the probability of conception, survival of the pregnancy, and sex of the baby. - The New England Journal of Medicine 333: 1517-1521.

Williams, K. M., Cooper, B. S., Howell, T. M., Yuille, J. C. \& Paulhus, D. L. 2009: Inferring sexually deviant behavior from corresponding fantasies. The role of personality and pornography consumption - Criminal Justice and Behavior 36: 198-222. 